\title{
Synthesis of oleic-imidazoline and investigation on its inhibition efficiency for the corrosion of low carbon steel in chloride environments
}

\author{
D.U.C Rahayu, ${ }^{1 *}$ Y.K. Krisnandi, ${ }^{1}$ B.H. Susanto, ${ }^{2}$ I. Abdullah, ${ }^{1}$ \\ D.A. Nurani, ${ }^{1}$ I.R. Saragi, ${ }^{1,3}$ A. Yuniastuti, ${ }^{1}$ M. Mujahiduzzakka, ${ }^{1}$ \\ S. Cahyani, ${ }^{1}$ S. Fitriani, ${ }^{1}$ F.G. Nurchanifah, ${ }^{1}$ R.A. Fadhilsyah, ${ }^{1}$ \\ B. Purnomo ${ }^{4}$ and A.P. Gustianthy ${ }^{4}$ \\ ${ }^{1}$ Department of Chemistry, Faculty of Mathematics and Natural Sciences (FMIPA), \\ Universitas Indonesia, Depok 16424, Indonesia \\ ${ }^{2}$ Department of Chemical Engineering, Faculty of Engineering, Universitas Indonesia, \\ Depok 16424, Indonesia \\ ${ }^{3}$ Department of Chemistry, Faculty of Mathematics and Natural Sciences (FMIPA), \\ Universitas Sumatera Utara, Medan 20155, Indonesia \\ ${ }^{4}$ PT Pertamina Research and Technology Center, Jl. Raya Bekasi Km.20, Pulogadung, \\ Jakarta 13920, Indonesia \\ *E-mail: dyahutamicr@sci.ui.ac.id
}

\begin{abstract}
Carbon steel is the principal material used in oil and gas production pipelines. However, carbon steel is vulnerable to corrosion by corrosive media it contacts, and this causes economic losses. The corrosion rate of carbon steel is inhibited by imidazoline, an organic corrosion inhibitor. In this study, oleic-imidazoline was successfully synthesized from triethylenetetramine and oleic acid under reflux at $100-140^{\circ} \mathrm{C}$ for $12 \mathrm{~h}$. The synthesized compound was characterized for its structure by using FTIR, UV-Vis, NMR $\left({ }^{1} \mathrm{H}\right.$ and $\left.{ }^{13} \mathrm{C}\right)$, and LC-MS/MS spectral data. Oleicimidazoline showed a maximum absorption peak at a wavelength of $203.8 \mathrm{~nm}$ (UV-Vis), absorption peaks at $1656.51 \mathrm{~cm}^{-1}$ belonging to $\mathrm{C}=\mathrm{N}$ bond (FTIR), a peak at a chemical shift of 2.17 and $3.30-3.48 \mathrm{ppm}$ indicating $\underline{\mathrm{H}}-\mathrm{C}-\mathrm{C}=\mathrm{N}$ and imidazoline ring proton, respectively $\left({ }^{1} \mathrm{H}\right.$ NMR), and a peak at the chemical shift of $164.6 \mathrm{ppm}$ fitting $\mathrm{C}=\mathrm{N}\left({ }^{13} \mathrm{C} \mathrm{NMR}\right)$. LC-MS/MS showed that oleic-imidazoline was a major component in the synthesized compound with $[\mathrm{M}+\mathrm{H}]^{+} 393.37 \mathrm{~m} / \mathrm{z}$ at $\mathrm{rt} 10.87 \mathrm{~min}$. The oleic-imidazoline's performance as a corrosion inhibitor toward low carbon steel in a $1 \% \mathrm{NaCl}$ solution was measured using two methods, which are Tafel polarization and weight loss. The highest inhibition efficiency percentage (\%IE) resulted from the two methods are $83.26 \%$ and $83.33 \%$, respectively. Oleic-imidazoline reveals good performance to inhibit the corrosion since this compound undergoes physisorption with slight chemisorption on low carbon steel in chloride environment.
\end{abstract}

Received: July 16, 2021. Published: September 10, 2021

doi: $\underline{10.17675 / 2305-6894-2021-10-3-25}$

Keywords: chloride environment, corrosion inhibitor, low carbon steel, oleic-imidazoline. 


\section{Introduction}

Carbon steel is the most commonly used material in oil and gas pipelines for production lines. Because of its corrosive medium, however, carbon steel is susceptible to corrosion, resulting in financial losses [1]. Therefore, one of the organic corrosion inhibitors, imidazoline, has been used to slow the corrosion rate of carbon steel [2]. Imidazoline is a heterocyclic compound containing high electron density centres, which leads to the protection of metal surfaces from corrosion [3]. The addition of heterocyclic compound as a corrosion inhibitor has recently become more popular since the use of this compound leads to a more biodegradable, inexpensive, and environmentally friendly corrosion control technique [4]. A corrosion inhibitor based on the imidazoline scaffold affects anodic and cathodic reactions with the adsorption process on metal surfaces [5]. Furthermore, imidazoline has a good adsorption character and can form a protective layer (film) on metal surfaces and a monolayer that has hydrophobic properties [6-8].

Research on the structural modification of imidazoline (especially oleic-imidazoline) as a corrosion inhibitor has been carried out. Zhao et al., (2016) had synthesized oleicimidazoline from oleic acid (OA) and various polyamines such as ethylenediamine (EDA), diethylenetriamine (DETA), triethylenetetramine (TETA), tetraethylenepentamine (TEPA), polyethylenepolyamine (PEPA) and aminoethylethanolamine (AEEA). The hydroxyethyl group in the pendant chain can increase the hydrophilicity, whereas the aminoethyl group will increase the hydrophobicity. Oleic-imidazoline which showed the highest activity as a corrosion inhibitor on the oil field in China was from DETA and TETA [9]. Modification of oleic-imidazoline from DETA had been intensively carried out to form quaternary oleicimidazoline which showed a $99.113 \%$ corrosion inhibition rate in hydrochloric acid [10]. Furthermore, oleic-imidazoline from TEPA and ester form of oleic-imidazoline from AEEA showed a good performance as a corrosion inhibitor in $1 \% \mathrm{NaCl}[11,12]$. In addition, oleicimidazoline from DETA, AEEA and TETA exhibited high activity to inhibit the corrosion in sulfuric acid with the addition of inorganic salts, i.e. KI, KCNS and $\mathrm{KCl}$ [13]. All the aforementioned research above revealed that oleic-imidazoline had a good potential to inhibit corrosion. Therefore, in this study, synthesis of oleic-imidazoline from TETA and technical grade of OA was conducted followed by investigating its anticorrosion activity in chloride environment. TETA was chosen as polyamines since oleic-imidazoline synthesized from TETA for both structural elucidation and its corrosion inhibition activity is still limited. Meanwhile, the technical grade of OA was selected since it was economically friendly, which has the potential to be used in the industrial scale. Synthesizing and developing oleicimidazoline could provide an alternative for organic corrosion inhibitor uses for both research and industrial applications. 


\section{Experimental}

\subsection{General}

The chemicals used for synthesis, test, and analysis were triethylenetetramine (TETA), $\mathrm{NaCl}, \mathrm{CH}_{2} \mathrm{Cl}_{2}$, acetone, methanol $(\mathrm{MeOH}), \mathrm{NH}_{4} \mathrm{OH} 25 \%$, and $\mathrm{Na}_{2} \mathrm{SO}_{4}$ anhydrous purchased from Merck, while the technical grade of oleic acid (OA) from PT. Brataco Chemika with a composition of $80.80 \%$ OA, $<18 \%$ linoleic acid (LNA), and $<6 \%$ stearic acid (SA). All chemicals were used without any purification before use. Oleic-imidazoline was synthesized by reflux method which required a three-neck round-bottom flask, condenser, oil bath, magnetic stirrer, hot plate, and thermometer. The reaction was monitored using thin-layer chromatography (TLC) on precoated $0.25 \mathrm{~mm}$ thickness of Si $60 \mathrm{GF}_{254}$ plates (Merck) and TLC spots were visualized under $\mathrm{UV}_{254}$. The corrosion inhibition activity tests were performed using an electrochemical method with an eDAQ 450 potentiostat-Versasatat II and gravimetric method. The materials used for corrosion inhibition activity tests were a low carbon steel JIS G3123 grade SGD 400D with a diameter of $5 \mathrm{~mm}$ and a length of 4-5 cm obtained from PT. Citra Tanamas with a composition of C $0.08 \%, 0.40 \% \mathrm{Mn}, 0.19 \% \mathrm{Si}$, $0.033 \% \mathrm{P}, 0.021 \% \mathrm{~S}$, and $99.276 \% \mathrm{Fe}$ as working electrode (WE), SCE as reference electrode (RE), and platinum as auxiliary electrode (AE). As a comparison, the commercial sample of corrosion inhibitor was obtained from PT. Pertamina (Persero). UV-Vis Shimadzu UV2540 in MeOH spectroscopic grade (Merck), FTIR Shimadzu IR Prestige 2 in KBr pellet (Merck), $500 \mathrm{MHz}$ NMR Bruker Avance operating at $500 \mathrm{MHz}\left({ }^{1} \mathrm{H}\right)$ and $125 \mathrm{MHz}\left({ }^{13} \mathrm{C}\right)$ in $\mathrm{CDCl}_{3}$ (Merck), and LC-MS/MS with LC system ACQUITY UPLC ${ }^{\circ} \mathrm{H}-\mathrm{Class}$ System (Waters, USA) and MS Xevo G2-S QTof (Waters, USA) in MeOH spectroscopic grade (Merck) with the addition of formic acid (Merck) were used for structural elucidation of oleic-imidazoline. LC-MS/MS parameters were adapted from previous research [14].

\subsection{Synthesis of oleic-imidazoline}

Oleic-imidazoline was synthesized from TETA (5 mmol) and OA (5 mmol) in a three-neck round-bottom flask connected to a condenser equipped with a magnetic stirrer and thermometer. After heating with reflux at $100-140^{\circ} \mathrm{C}$ for 12 hours, the mixture then was worked up by extraction by using $\mathrm{CH}_{2} \mathrm{Cl}_{2}$ : brine solution $(1: 1, \mathrm{v} / \mathrm{v})$ to collect the organic layer. The organic layer then was dried using $\mathrm{Na}_{2} \mathrm{SO}_{4}$ anhydrous, evaporated, and stored in a desiccator. The synthesized compound then was identified using TLC with $\mathrm{CH}_{2} \mathrm{Cl}_{2}: \mathrm{MeOH}$ $(8: 2, \mathrm{v} / \mathrm{v})$ with one drop of $\mathrm{NH}_{4} \mathrm{OH} 25 \%$ as an eluent, and further characterized by using FTIR, UV-Vis, NMR $\left({ }^{1} \mathrm{H}\right.$ and $\left.{ }^{13} \mathrm{C}\right)$, and LC-MS/MS.

Oleic-imidazoline was obtained as dark-brown oily-solid, $R_{\mathrm{f}} 0.80$ in $\mathrm{CH}_{2} \mathrm{Cl}_{2}: \mathrm{MeOH}$ $(8: 2, \mathrm{v} / \mathrm{v})$ with one drop of $\mathrm{NH}_{4} \mathrm{OH} 25 \%$; FTIR (KBr pellet) $v_{\max }\left(\mathrm{cm}^{-1}\right): 3291.83(\mathrm{~N}-\mathrm{H})$, $3008.25\left(\mathrm{C}-\mathrm{H} \mathrm{sp}^{2}\right), 2924.75-2853.07\left(\mathrm{C}-\mathrm{H} \mathrm{sp}^{3}\right), 1656.51(\mathrm{C}=\mathrm{N}), 1643.12(\mathrm{C}=\mathrm{C}), 1547.80$ $(\mathrm{N}-\mathrm{H}), 1465.09-1375.29\left(\mathrm{C}-\mathrm{H} \mathrm{sp}^{3}\right), 1271.31(=\mathrm{C}-\mathrm{N}), 723.84($ cis $\mathrm{C}-\mathrm{H}) ; \mathrm{UV}-\mathrm{V}$ is $(\mathrm{MeOH})$ $\lambda_{\max }(\mathrm{nm}): 203.8 ;{ }^{1} \mathrm{H} \mathrm{NMR}\left(500 \mathrm{MHz}, \mathrm{CDCl}_{3}\right) \delta(\mathrm{ppm}): 5.33(2 \mathrm{H}, q, 7 \mathrm{~Hz}), 4.23(3 \mathrm{H}$, br s), 
3.62-3.26 (4H, m), 2.92-2.42 (8H, m), $2.16(2 \mathrm{H}, t, 7 \mathrm{~Hz}), 2.01(4 \mathrm{H}, q, 7 \mathrm{~Hz}), 1.59(2 \mathrm{H}, q i$, $9.5 \mathrm{~Hz}), 1.37-1.24(20 \mathrm{H}, m), 0.87(3 \mathrm{H}, t, 7 \mathrm{~Hz}) ;{ }^{13} \mathrm{C} \mathrm{NMR}\left(125 \mathrm{MHz}, \mathrm{CDCl}_{3}\right) \delta(\mathrm{ppm})$ : 164.6, 130.1, 129.9, 56.7, 54.3, 54.1, 53.2, 52.9, 52.9, 32.0, 29.9, 29.8 (4C), 29.7, 29.5, 29.4, 29.3 (2C), 27.3, 25.7, 22.8, 14.3; and LC-MS/MS (MeOH-HCOOH): dominant LC rt $10.87 \mathrm{~min}, \mathrm{MS}(25-60 \mathrm{eV}, \mathrm{m} / \mathrm{z}): 393.37[\mathrm{M}+\mathrm{H}]^{+}$calculated as $\mathrm{C}_{24} \mathrm{H}_{49} \mathrm{~N}_{4}{ }^{+}, 376.34,349.33$, 320.30, 308.30, 306.28 (base peak), 280.26, 268.27, 254.25, 238.22, 224.20, 210.19, 196.17, 184.16, 170.13, 156.13, 141.10, 127.09, 113.07, 98.06, 87.09, 71.06.

\subsection{Tafel polarization method}

Electrochemical measurements were conducted using the cyclic voltammetry method in a $1 \% \mathrm{NaCl}$ saturated with $\mathrm{CO}_{2}$ based on previous work [11]. Three electrodes, WE, RE, and $\mathrm{AE}$, were arranged as an electrochemical cell in a beaker glass which contained corrosion medium solution in the absence and presence of various concentrations of corrosion inhibitor $(100-500 \mathrm{ppm})$. The potentiodynamic polarization then was recorded within the potential range of -2000 to $+500 \mathrm{mV}$ at a potential scan rate of $50 \mathrm{mV} / \mathrm{s}$. The electrochemical parameters and the percentage of inhibition efficiency (\%IE) were obtained by using the Tafel polarization which was processed by using Equation 1 while the corrosion rate $\left(C_{\mathrm{R}}\right.$ in $\left.\mathrm{mm} \cdot \mathrm{y}^{-1}\right)$ was evaluated using Equation 2, where $I_{\text {corr }}^{0}$ and $I_{\text {corr }}\left(\mathrm{mA} / \mathrm{cm}^{2}\right)$ is corrosion current densities in the absence and presence of corrosion inhibitor, respectively, $K$ represents rate constant, $E W$ represents equivalent weight in g/equiv., $d$ represents tested low carbon steel density $\left(\mathrm{g} / \mathrm{cm}^{3}\right)$, whereas $A$ is the area of the sample $\left(\mathrm{cm}^{2}\right)$.

$$
\begin{aligned}
\% I E & =\left(1-\frac{I_{\text {corr }}}{I_{\text {corr }}^{0}}\right) \cdot 100 \\
C_{\mathrm{R}} & =\frac{I_{\text {corr }} \cdot K \cdot E W}{d \cdot A}
\end{aligned}
$$

\subsection{Weight loss method}

Gravimetric measurements were carried out in a $1 \% \mathrm{NaCl}$ environment in the presence of various concentrations of corrosion inhibitor $(100-500 \mathrm{ppm})$. The soaking time was adjusted for $6 \mathrm{~h}$ at room temperature. After soaking, low carbon steel was removed from the corrosion medium solution and washed with bi-distilled water and acetone, then dried and weighed. The results obtained then were compared with low carbon steel immersed in the corrosion medium without the addition of oleic-imidazoline. The $C_{\mathrm{R}}\left(\mathrm{mm} \cdot \mathrm{y}^{-1}\right)$ and $\% I E$ were calculated following Equations 3 and 4, respectively, where $W$ represents weight loss (mg), $d$ represents tested low carbon steel density $\left(\mathrm{g} / \mathrm{cm}^{3}\right), A$ represents the area of the sample $\left(\mathrm{cm}^{2}\right), t$ represents the time of exposure (h), whereas $v_{\mathrm{o}}$ and $v\left(\mathrm{~mm} \cdot \mathrm{y}^{-1}\right)$ are the corrosion rates in the absence and presence of corrosion inhibitor, respectively. 


$$
\begin{gathered}
C_{\mathrm{R}}=\frac{87.6 \cdot W}{d \cdot A \cdot t} \\
\% I E=\frac{v_{0}-v}{v_{0}} \cdot 100
\end{gathered}
$$

\subsection{Corrosion Protection Mode Analysis of Oleic-Imidazoline}

Analysis of corrosion protection mode of oleic imidazoline was carried out by extracting the corrosion medium solution using $\mathrm{CH}_{2} \mathrm{Cl}_{2}$ : brine solution $(1: 1, \mathrm{v} / \mathrm{v})$. The collected organic layer then was identified using TLC with the same condition as previously stated. Further, FTIR characterization was also conducted.

\section{Results and Discussion}

\subsection{Oleic-imidazoline synthesis}

In this present study, oleic-imidazoline from TETA and technical grade of OA was successfully synthesized using reflux following the reaction scheme illustrated in Figure 1. According to Figure 1, the formation of oleic-imidazoline consisted of two steps, i.e. amidation and cyclization, which involved water elimination in both steps [15]. The using of technical grade of OA will produce oleic-imidazoline in a mixture with other fatty acidimidazoline, such as linoleic-imidazoline and stearic-imidazoline, but the predominant synthesized compound was oleic-imidazoline, which was confirmed by using FTIR, UV-Vis, NMR $\left({ }^{1} \mathrm{H}\right.$ and $\left.{ }^{13} \mathrm{C}\right)$, and LC-MS/MS spectral data.

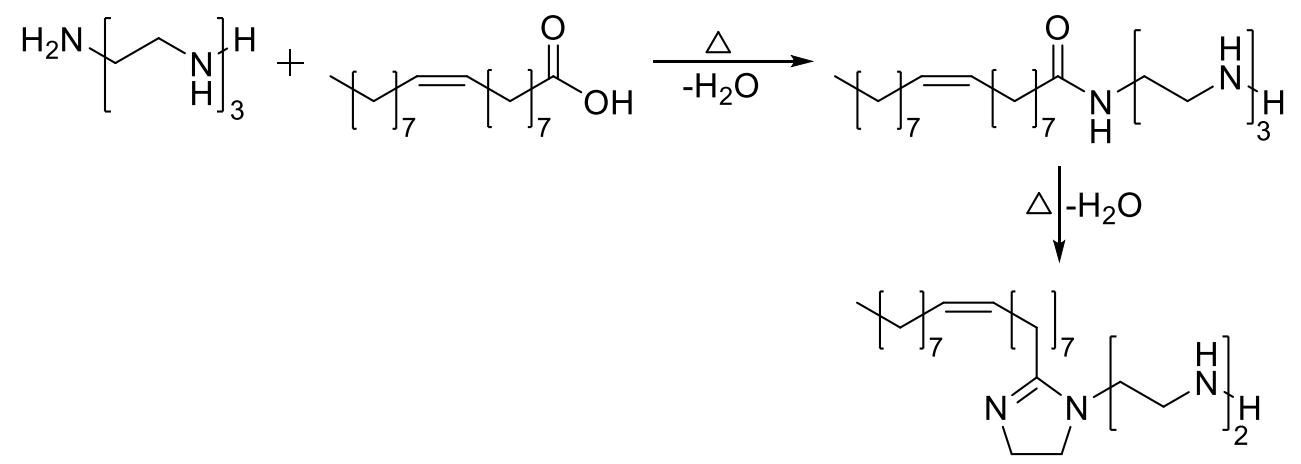

Figure 1. Reaction scheme of oleic-imidazoline synthesis.

FTIR spectra of oleic-imidazoline showed characteristic peaks of imidazoline at wavenumber $\left(v_{\max }\right)$ of 1656.51 and $1271.31 \mathrm{~cm}^{-1}$ indicated $\mathrm{C}=\mathrm{N}$ and $=\mathrm{C}-\mathrm{N}$ in imidazoline ring, respectively. In addition, the hydrocarbon chain in the synthesized compound which was formed from unsaturated fatty acid exhibited absorption peaks at $v_{\max }$ of 3008.25 $\left(\mathrm{C}-\mathrm{H} \mathrm{sp}^{2}\right), 1643.12(\mathrm{C}=\mathrm{C})$, and $723.84 \mathrm{~cm}^{-1}$ (cis $\left.\mathrm{C}-\mathrm{H}\right)$ together with 2924.75-2853.07 (stretching $\mathrm{C}-\mathrm{H} \mathrm{sp}{ }^{3}$ ) and $1465.09-1375.29 \mathrm{~cm}^{-1}$ (bending $\mathrm{C}-\mathrm{H} \mathrm{sp}{ }^{3}$ ). This compound also showed peaks for stretching $\mathrm{N}-\mathrm{H}$ and bending $\mathrm{N}-\mathrm{H}$ at $v_{\max }$ of 3291.83 and 1547.80, 
respectively, belonging to the pendant group [16]. Moreover, maximum absorbance in UV-Vis spectra of oleic-imidazoline appeared at the wavelength $\left(\lambda_{\max }\right)$ of $203.8 \mathrm{~nm}$, specified as $\mathrm{C}=\mathrm{N}$ from imidazoline moiety [11-12].

Further characterization then was carried out by using NMR. ${ }^{1} \mathrm{H}$ NMR $(500 \mathrm{MHz}$, $\mathrm{CDCl}_{3}$ ) exhibited characteristic peaks of imidazoline scaffold from unsaturated fatty acid $[9,17]$. Peaks at a chemical shift $\left(\delta_{\mathrm{H}}\right)$ of $3.62-3.26 \mathrm{ppm}(4 \mathrm{H}, m)$ indicated the formation of the imidazoline ring, whereas peaks at $\delta_{\mathrm{H}} 2.16 \mathrm{ppm}(2 \mathrm{H}, t, 7 \mathrm{~Hz})$ showed the proton on hydrocarbon chain nearest to the imidazoline ring $(\underline{\mathrm{H}}-\mathrm{C}-\mathrm{C}=\mathrm{N})$. Other protons indicating an unsaturated hydrocarbon chain had appeared at $\delta_{\mathrm{H}} 5.33(2 \mathrm{H}, q, 7 \mathrm{~Hz})$ for proton attached on $\mathrm{C}=\mathrm{C}$ alkene, $2.01(4 \mathrm{H}, q, 7 \mathrm{~Hz})$ for proton adjacent to $\mathrm{C}=\mathrm{C}$ alkene, and the rest at $\delta_{\mathrm{H}} 1.59$ $(2 \mathrm{H}, q i, 9.5 \mathrm{~Hz}), 1.37-1.24(20 \mathrm{H}, m), 0.87 \mathrm{ppm}(3 \mathrm{H}, t, 7 \mathrm{~Hz})$ for the remaining hydrocarbon chain. In addition, peaks from the pendant group pointed at $\delta_{\mathrm{H}} 2.92-2.42(8 \mathrm{H}, m)$ correlated to four $-\mathrm{CH}_{2}$ groups attached to the nitrogen atom which having proton appeared at $\delta_{\mathrm{H}} 4.23$ $(3 \mathrm{H}$, br s $) .{ }^{13} \mathrm{C} \mathrm{NMR}\left(125 \mathrm{MHz}, \mathrm{CDCl}_{3}\right)$ showed a specific peak of imidazoline-derived at a chemical shift $\left(\delta_{\mathrm{C}}\right)$ of $164.6 \mathrm{ppm}$ belonging to $\mathrm{C}=\mathrm{N}$ [18]. Moreover, peaks at $\delta_{\mathrm{C}} 130.1$ and $129.9 \mathrm{ppm}$ indicated the $\mathrm{C} \mathrm{sp^{2 }}$ from $\mathrm{C}=\mathrm{C}$ alkene in the unsaturated hydrocarbon chain. Actually, in the $\mathrm{C} \mathrm{sp}{ }^{2}$ region $\left(\delta_{\mathrm{C}} 130.4-128.0 \mathrm{ppm}\right)$, there were additional four peaks correlated to two alkenes from linoleic-imidazoline, as another constituent of synthesized oleic-imidazoline from the technical grade of OA. In addition, peaks at $\delta_{\mathrm{C}} 56.7-52.9 \mathrm{ppm}$ corresponded to $\mathrm{C} \mathrm{sp}^{3}$ bonded to the nitrogen atom in both imidazoline ring and pendant group, while peaks at $\delta_{\mathrm{C}} 32.0-14.3 \mathrm{ppm}$ indicated $\mathrm{C} \mathrm{sp}^{3}$ in the hydrocarbon chain.

To analyze the oleic-imidazoline composition, LC-MS/MS spectra were recorded. LC chromatogram of oleic-imidazoline exhibited predominant peak $(>80 \%)$ at a retention time (rt) of $10.87 \mathrm{~min}$ represented oleic-imidazoline with $[\mathrm{M}+\mathrm{H}]^{+} 393.37 \mathrm{~m} / \mathrm{z}$, calculated as $\mathrm{C}_{24} \mathrm{H}_{49} \mathrm{~N}_{4}{ }^{+}$. The proposed selected fragmentation of oleic-imidazoline was illustrated in Figure 2. Two minor peaks were also observed at $\mathrm{rt} 10.52$ and $11.52 \mathrm{~min}$ for linoleic$\left([\mathrm{M}+\mathrm{H}]^{+} \quad 391.38 \mathrm{~m} / \mathrm{z}, \quad \mathrm{C}_{24} \mathrm{H}_{47} \mathrm{~N}_{4}{ }^{+}\right)$and stearic-imidazoline $\left([\mathrm{M}+\mathrm{H}]^{+} \quad 395.38 \mathrm{~m} / \mathrm{z}\right.$, $\mathrm{C}_{24} \mathrm{H}_{51} \mathrm{~N}_{4}{ }^{+}$), respectively. Oleic-imidazoline exhibited $\mathrm{rt}$ between linoleic- and stearicimidazoline since it was less polar than linoleic-imidazoline but more polar compared to stearic-imidazoline. All the spectrum data indicated that oleic-imidazoline had been successfully synthesized. 


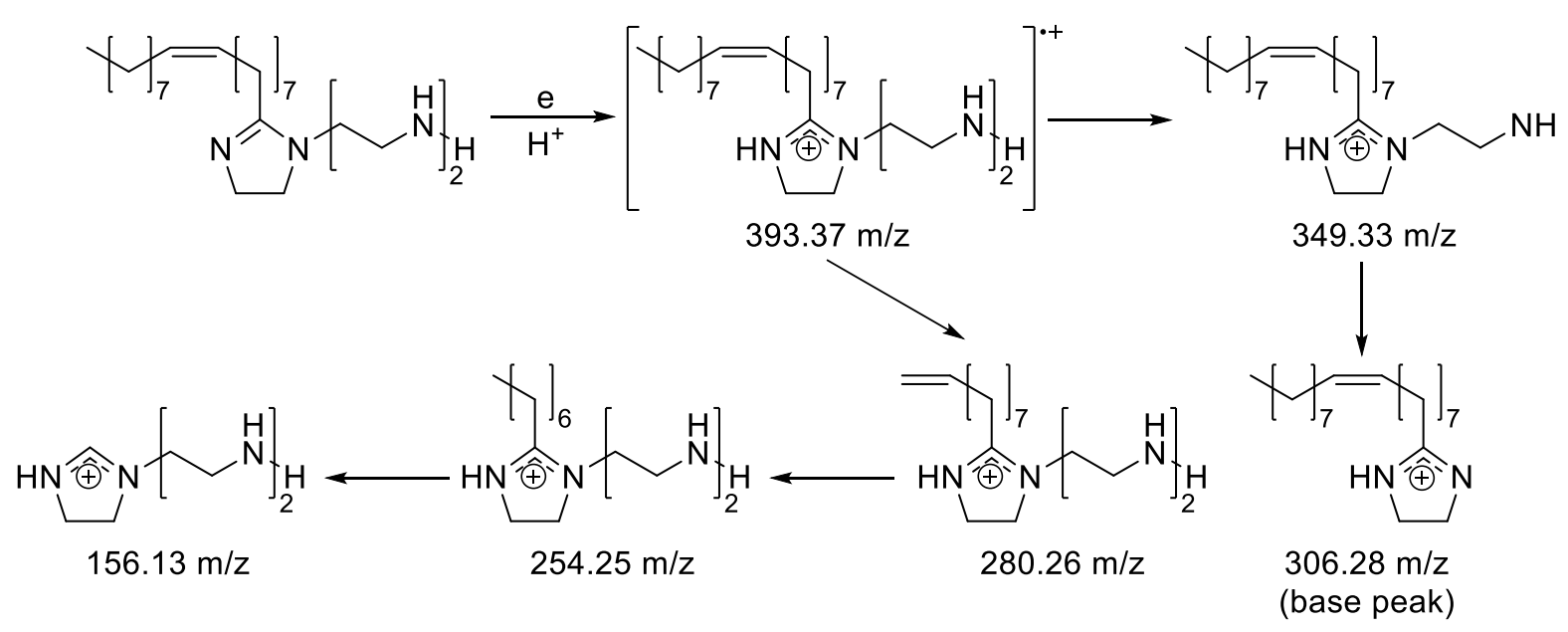

Figure 2. Proposed selected fragmentation scheme of oleic-imidazoline.

\subsection{Effect of inhibitor's concentration on Tafel polarization analysis}

Tafel polarization curves of the oleic-imidazoline and commercial sample were displayed in Figure 3. Oleic-imidazoline was found to be effective in inhibiting the corrosion of low carbon steel in chloride environments similar to commercial sample. Figure 4 displayed the $\% I E$ and $C_{\mathrm{R}}$ of both corrosion inhibitors as a function of the inhibitor concentration used on the Tafel polarization method. According to Figure 4, the $C_{\mathrm{R}}$ decreased and therefore the $\% I E$ improved as the inhibitor concentration was increased. This result exhibited that inhibitor is adsorbed to a larger degree on the metal surface as the inhibitor concentration is increased, which leads to the restriction of interaction between corrosive environment and metal surface [3, 19]. Oleic-imidazoline and commercial sample at $500 \mathrm{ppm}$ demonstrated the best $\% I E$ as 83.26 and $84.41 \%$, respectively. A slight difference in \%IE makes the synthesized oleic-imidazoline can be used as an alternative corrosion inhibitor.
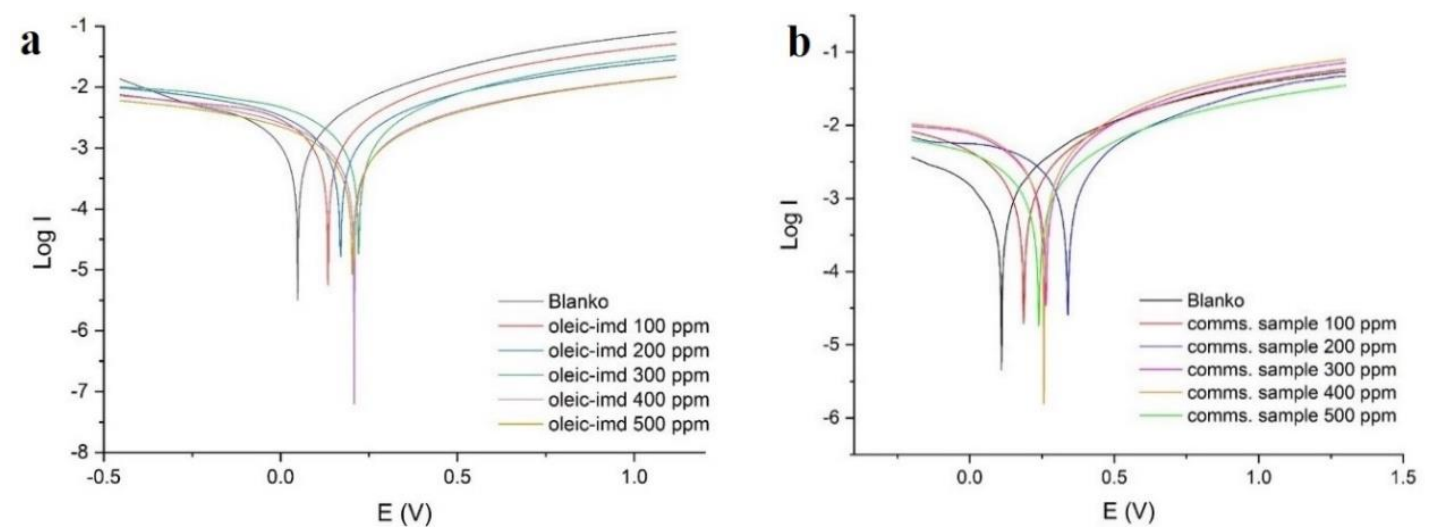

Figure 3. Tafel polarization curves of oleic-imidazoline (a) and commercial sample (b). 

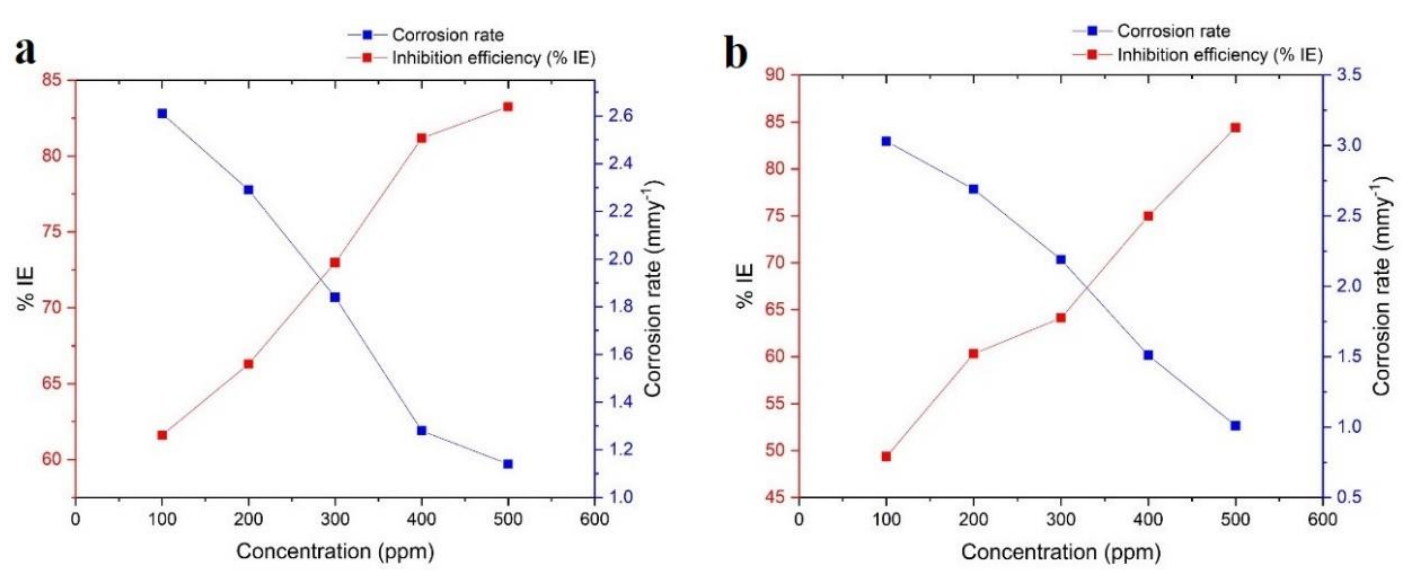

Figure 4. Corrosion rate and percentage of inhibition efficiency with various concentration of oleic-imidazoline (a) and commercial sample (b) using Tafel polarization method.

\subsection{Effect of inhibitor's concentration on weight loss analysis}

The $\% I E$ and $C_{\mathrm{R}}$ of oleic-imidazoline and commercial sample as a function of the inhibitor concentration used on weight loss method was presented in Figure 5. Based on Figure 5, similar trends on \%IE and $C_{\mathrm{R}}$ were observed with the previous inhibition corrosion method. With this method, oleic-imidazoline demonstrated a slightly higher $\% I E$ at $500 \mathrm{ppm}$ $(83.33 \%)$ than the commercial sample at the same concentration $(500 \mathrm{ppm}, 80.00 \%)$. The higher \%IE of oleic-imidazoline was due to the interaction between electron-donating groups such as imidazoline ring, amino groups in pendant chain, and double-bond ( $\pi$-electron) in imidazoline ring and hydrocarbon chain [19].

Figure 6 plotted the comparison of the $\% I E$ as a function of the inhibitor concentration used for both Tafel polarization and weight loss methods. According to Figure 6, the \%IE obtained was not significantly different, especially in a higher concentration of inhibitor. The difference in \%IE was probably due to the longer immersion time in the weight loss method which can cause the dissolution of the linkage between metal and inhibitor making the increase of $C_{\mathrm{R}}$ [3]. However, both methods showed that the corrosion of low carbon steel in chloride environments was significantly reduced in the presence of an oleic-imidazoline inhibitor compound. 

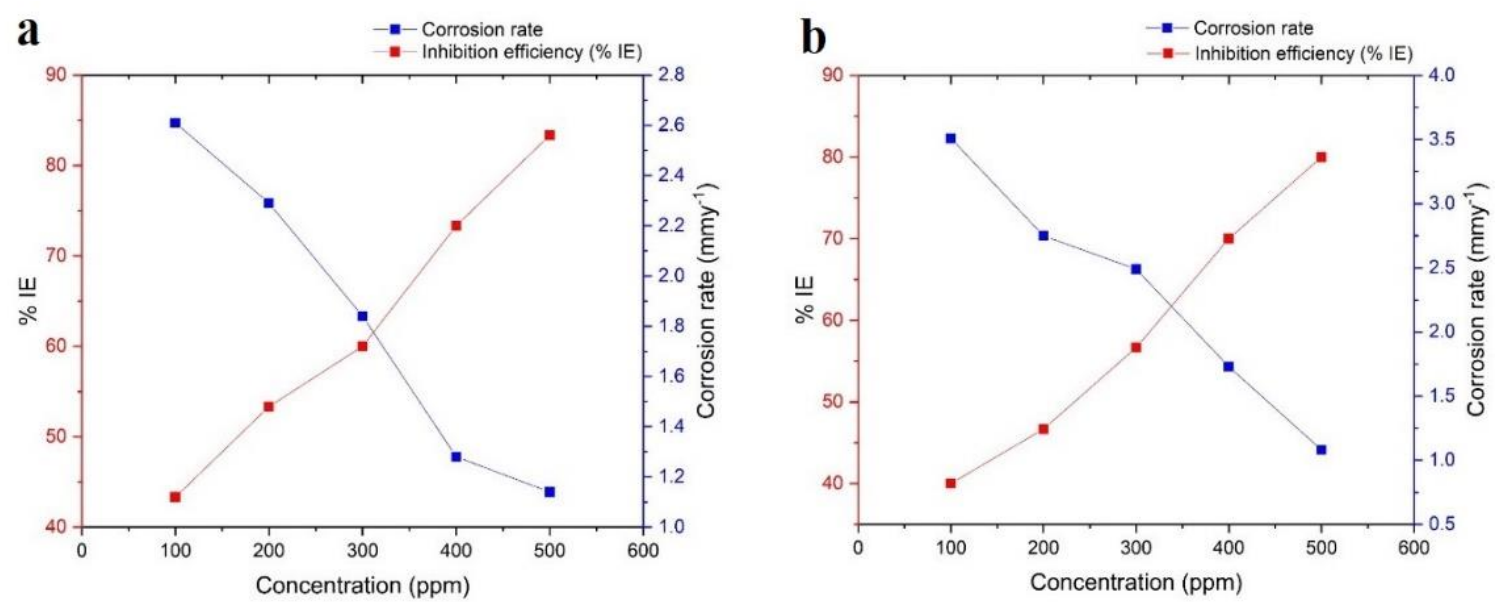

Figure 5. Corrosion rate and percentage of inhibition efficiency with various concentration of oleic-imidazoline (a) and commercial sample (b) using weight loss method.
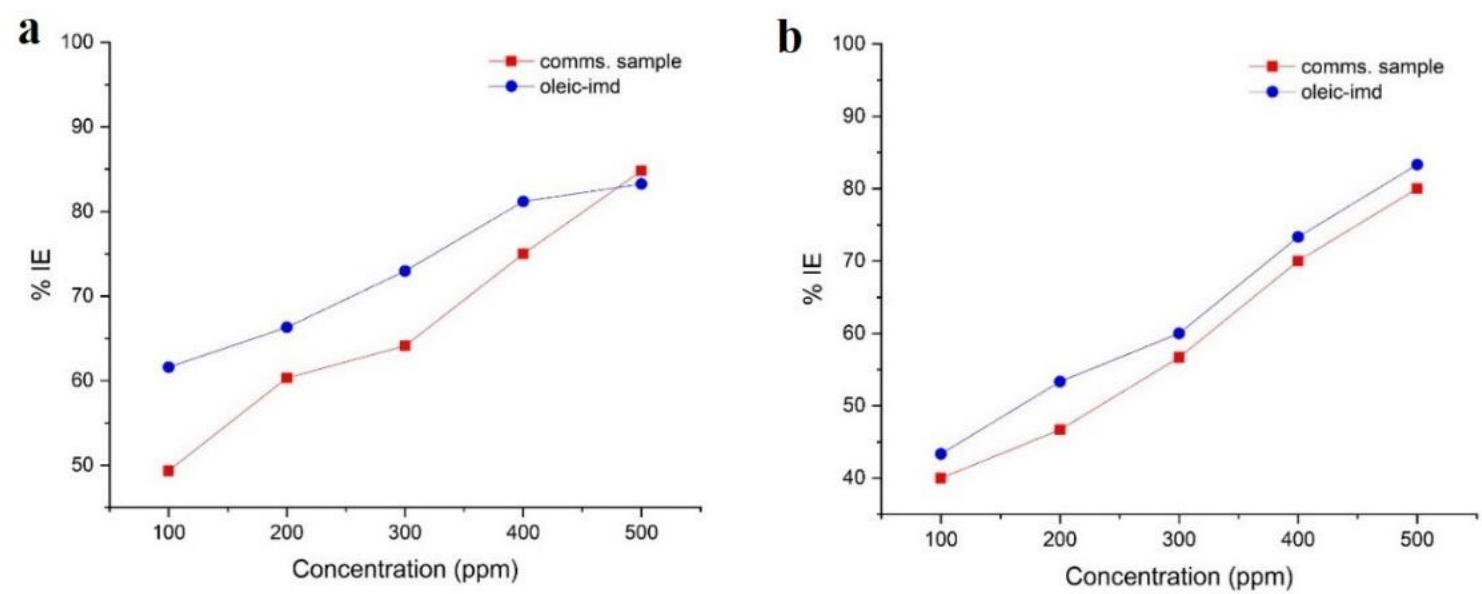

Figure 6. Corrosion inhibition activity of oleic-imidazoline and commercial sample in $1 \%$ $\mathrm{NaCl}$ using electrochemical (a) and gravimetric (b) methods.

\subsection{Corrosion protection mode analysis of oleic-imidazoline}

Analysis of corrosion protection mode of oleic-imidazoline was carried out after corrosion inhibition test by using FTIR. The FTIR spectra of oleic-imidazoline before and after corrosion test were presented in Figure 7. By comparing the FTIR spectra in Figure 7, it was observed that there were still typical peaks of imidazoline at $v_{\max } 1654.48$ and $1272.39 \mathrm{~cm}^{-1}$ belonging to $\mathrm{C}=\mathrm{N}$ and $=\mathrm{C}-\mathrm{N}$ in the imidazoline ring, respectively. In addition, it was also detected a new peak in low intensity at $v_{\max } 1725.37 \mathrm{~cm}^{-1}$ which indicated the structural change in oleic-imidazoline after the corrosion test. The new peak probably represents $\mathrm{C}=\mathrm{O}$ amide which indicates the hydrolysis process during the corrosion test (Figure 8). However, since there were still characteristic peaks of imidazoline and only slightly altered the imidazoline ring structure, it can be stated that the corrosion protection mode of oleic-imidazoline was physisorption with slight chemisorption [20]. 


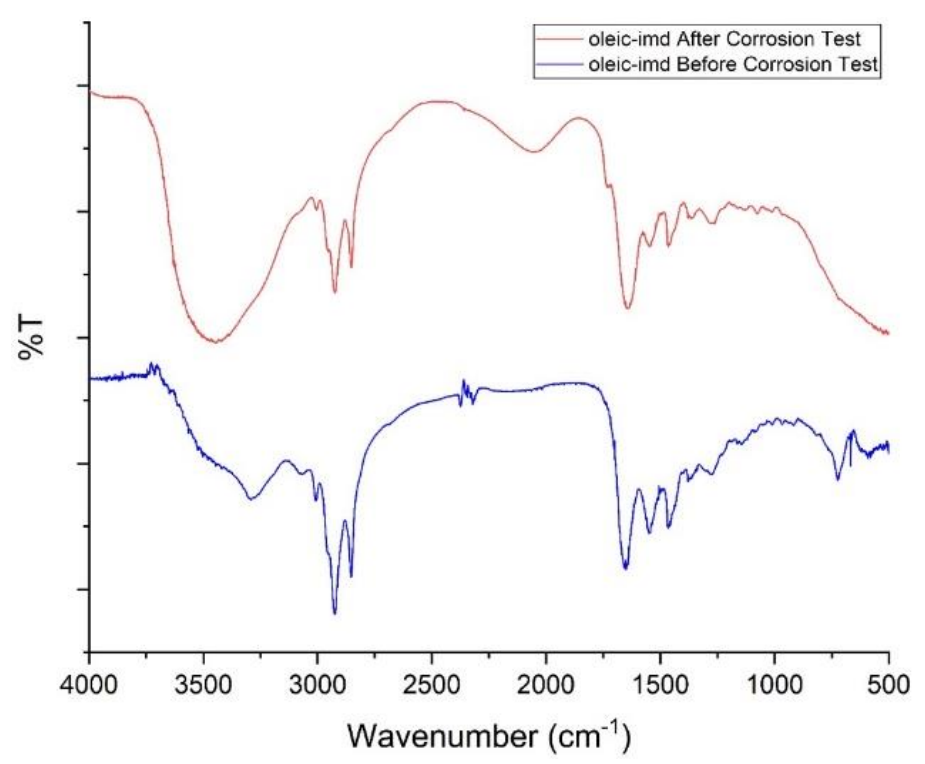

Figure 7. FTIR spectra of oleic-imidazoline before and after corrosion test.

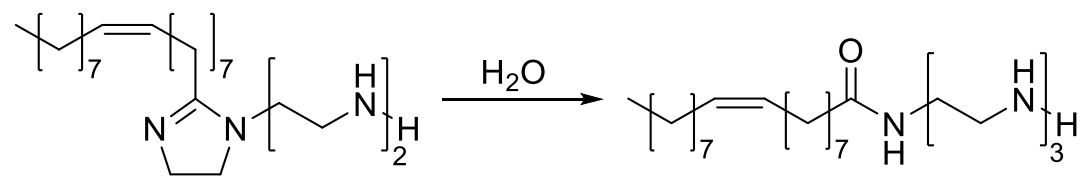

Figure 8. Proposed structural changes of oleic-imidazoline after a corrosion test.

The corrosion protection mode of oleic-imidazoline was found in agreement with the other organic corrosion inhibitor containing high electron density and long hydrophobic chains [13]. The proposed mechanism of oleic-imidazoline's performance on inhibiting corrosion on the metal surface was illustrated in Figure 9. Oleic-imidazoline has $\pi$-electron and $\mathrm{N}$ heteroatoms which are rich in lone pairs, making the adsorption of imidazoline on the metal surface. Meanwhile, the hydrocarbon chain forms a hydrophobic layer as a protective film on the metal surface which can block the active site of corrosion on the metal surface from the corrosive environment [21-23]. The adsorption behavior of the protective film is determined by the electrostatic interaction between the heteroatom and the double bond of the corrosion inhibitor and the metal surface $[20,24]$. The protective layer of the inhibitor will break the corrosion linkage which allows the $\pi$-electron donor of imidazoline to the empty orbital of the metal surface resulting in the higher value of \%IE [21]. The high \%IE value of oleic-imidazoline is summarized due to the barrier effect of physical and chemical interactions from the heteroatoms with the metal surface. 


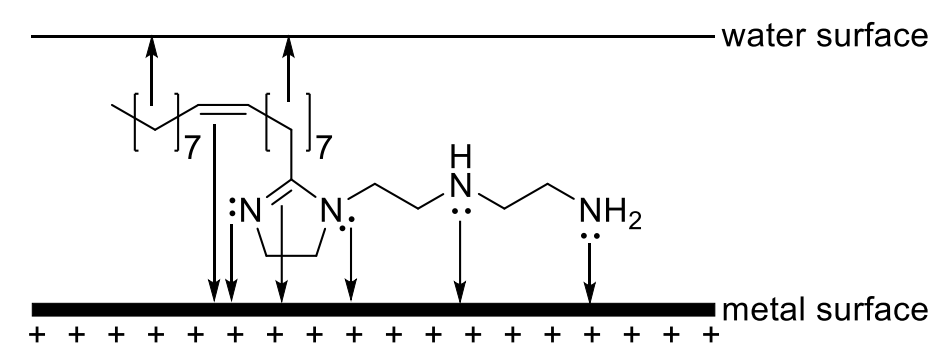

Figure 9. Proposed mechanism of oleic-imidazoline absorption on metal surfaces.

\section{Conclusions}

In this research, oleic-imidazoline was successfully synthesized by reacting triethylenetetramine (TETA) and technical grade of oleic acid (OA) under reflux for $12 \mathrm{~h}$ at $100-140^{\circ} \mathrm{C}$. The structure of the synthesized compound was elucidated by using FTIR, UV-Vis, NMR $\left({ }^{1} \mathrm{H}\right.$ and ${ }^{13} \mathrm{C}$ ), and LC-MS/MS spectral data. The corrosion inhibitor activity test towards low carbon steel in a $1 \% \mathrm{NaCl}$ solution indicated that oleic-imidazoline can be used as a potential corrosion inhibitor compared with commercial sample with the highest inhibition efficiency percentage (\%IE) was 83.26 and $83.33 \%$ in $500 \mathrm{ppm}$ using Tafel polarization and weight loss methods, respectively. The corrosion protection mode of oleicimidazoline was physisorption with slight chemisorption since the corrosion inhibition test slightly altered the imidazoline ring structure.

\section{Acknowledgement}

This work was supported by collaboration between FMIPA Universitas Indonesia and PT. Pertamina (Persero) research grant No. 006/G40200/2020-S0.

\section{References}

1. S.S. Al-Shihry, A.R. Sayed and H.M. Abd El-lateef, Design and assessment of a novel poly(urethane-semicarbazides) containing thiadiazoles on the backbone of the polymers as inhibitors for steel pipelines corrosion in $\mathrm{CO}_{2}$-saturated oilfield water, J. Mol. Struct., 2020, 1201, 1-9. doi: 10.1016/j.molstruc.2019.127223

2. T. Hong and W.P. Jepson, Corrosion inhibitor studies in large flow loop at high temperature and high pressure, Corros. Sci., 2001, 43, no. 10, 1839-1849. doi: 10.1016/S0010-938X(01)00002-6

3. A. Alamiery, E. Mahmoudi and T. Allami, Corrosion inhibition of low-carbon steel in hydrochloric acid environment using a Schiff base derived from pyrrole: gravimetric and computational studies, Int. J. Corros. Scale Inhib., 2021, 10, no. 2, 749-765. doi: 10.17675/2305-6894-2021-10-2-17

4. K.A. Ismaili, S. EL Arouji, A. Abdellaoui, F. El Kamani, Z. Rais, M.F. Baba, M. Taleb, K.M. Emran, A. Zarrouk, A. Aouniti and B. Hammouti, Electrochemical and gravimetric studies of the corrosion inhibition of mild steel in $\mathrm{HCl}$ medium by cymbopogon nardus essential oil, Der Pharma Chem., 2001, 7, no. 10, 34-44. 
5. G. Zhang, C. Chen, M. Lu, C. Chai and Y. Wu, Evaluation of inhibition efficiency of an imidazoline derivative in $\mathrm{CO}_{2}$-containing aqueous solution, Mater. Chem. Phys., 2007, 105, no. 2-3, 331-340. doi: 10.1016/j.matchemphys.2007.04.076

6. F.G. Liu, M. Du, J. Zhang and M. Qiu, Electrochemical behavior of Q235 steel in saltwater saturated with carbon dioxide based on new imidazoline derivative inhibitor, Corros. Sci., 2009, 51, no. 1, 102-109. doi: 10.1016/j.corsci.2008.09.036

7. S.A. Umoren, Polypropylene glycol: A novel corrosion inhibitor for $\times 60$ pipeline steel in $15 \% \mathrm{HCl}$ solution, J. Mol. Liq., 2016, 219, 946-958. doi: 10.1016/j.molliq.2016.03.077

8. G. Bereket and A. Yurt, Inhibition of the corrosion of low carbon steel in acidic solution by selected quaternary ammonium compounds, Anti-Corros. Methods Mater., 2002, 49, no. 3, 210-220. doi: 10.1108/00035590210431764

9. J-M. Zhao, F. Gu, T. Zhao and R-J. Jiang, Corrosion inhibition performance of imidazoline derivatives with different pedant chains under three flow rates in highpressure $\mathrm{CO}_{2}$ environment, Res. Chem. Intermed., 2016, 42, no. 6, 5753-5764. doi: 10.1007/s11164-015-2401-y

10. F. Zhou, H. Wang and Q. Dai, Study on the compound of imidazoline corrosion inhibitor, IOP Conf. Ser. Earth Environ. Sci., 2018, 153, 1-11. doi: 10.1088/1755$1315 / 153 / 5 / 052001$

11. M. Mujahiduzzakka, D.U.C. Rahayu, D.A. Nurani and Y.K. Krisnandi, Synthesis of oleic imidazoline derivative using MAOS (microwave assisted organic synthesis) method as corrosion inhibitor towards carbon steel, AIP Conf. Proc., 2020, 2242, 1-6. doi: $10.1063 / 5.0008006$

12. M.I. Andra, D.U.C. Rahayu, I. Abdullah and Y.K. Krisnandi, Ester-imidazoline: Modification of imidazoline using MAOS (microwave assisted organic synthesis) method as corrosion inhibitor towards carbon steel, AIP Conf. Proc., 2020, 2242, no. 1, 1-5. doi: $10.1063 / 5.0008002$

13. A.G. Berezhnaya, E.S. Khudoleeva and V.V. Chernyavina, Some imidazolines and their mixtures with inorganic anions as inhibitors of acid corrosion of steel, Int. J. Corros. Scale Inhib., 2021, 10, no. 2, 649-661. doi: 10.17675/2305-6894-2021-10-2-11

14. D.U.C. Rahayu, D.A. Setyani, H. Dianhar and P. Sugita, Phenolic compounds from Indonesian white turmeric (Curcuma zedoaria) rhizomes, Asian J. Pharm. Clin. Res., 2020, 13, no. 7, 194-198. doi: 10.22159/ajpcr.2020.v13i7.38249

15. V.M. Abbasov, T.A. Mammadova, K.R. Veliyev and K.H. Kasamanli, Hydroxy- and aminoethyl imidazolines of cottonseed oil fatty acids as additives for diesel fuels, Open J. Synth. Theory Appl., 2015, 4, no. 2, 33-39. doi: 10.4236/ojsta.2015.42004

16. X. Kong, C. Qian, W. Fan and Z. Liang, Experimental and QSAR study on the surface activities of alkyl imidazoline surfactants, J. Mol. Struct., 2018, 1156, 164-171. doi: $\underline{10.1016 / j . m o l s t r u c .2017 .11 .102 ~}$ 
17. D. Bajpai and V.K. Tyagi, Synthesis and characterization of imidazolinium surfactants derived from tallow fatty acids and diethylenetriamine, Eur. J. Lipid Sci. Technol., 2008, 110, no. 10, 935-940. doi: 10.1002/ejlt.200800046

18. M.W.S. Jawich, G.A. Oweimreen and S.A. Ali, Heptadecyl-tailed mono- and bis-imidazolines: A study of the newly synthesized compounds on the inhibition of mild steel corrosion in a carbon dioxide-saturated saline medium, Corros. Sci., 2012, 65, 104-112. doi: 10.1016/j.corsci.2012.08.001

19. M.M. Solomon, S.A. Umoren, M.A. Quraishi and M. Salman, Myristic acid based imidazoline derivative as effective corrosion inhibitor for steel in $15 \% \mathrm{HCl}$ medium, J. Colloid Interface Sci., 2019, 551, 47-60. doi: 10.1016/j.jcis.2019.05.004

20. K. Zhang, W. Yang, B. Xu, Y. Liu, X. Yin and Y. Chen, Corrosion inhibition of mild steel by bromide-substituted imidazoline in hydrochloric acid, J. Taiwan Inst. Chem. Eng., 2015, 57, 167-174. doi: 10.1016/j.jtice.2015.05.021

21. Y. Tang, F. Zhang, S. Hu, Z. Cao, Z. Wu and W. Jing, Novel benzimidazole derivatives as corrosion inhibitors of mild steel in the acidic media. Part I: Gravimetric, electrochemical, SEM and XPS studies, Corros. Sci., 2013, 74, 271-282. doi: 10.1016/j.corsci.2013.04.053

22. A.I. Obike, P.C. Okafor, K.J. Uwakwe, X. Jiang and D. Qu, The inhibition of $\mathrm{CO}_{2}$ corrosion of $\mathrm{L} 360$ mild steel in $3.5 \% \mathrm{NaCl}$ solution by imidazoline derivatives, Int. J. Corros. Scale Inhib., 2018, 7, no. 3, 318-330. doi: 10.17675/2305-6894-2018-7-3-3

23. Ya.G. Avdeev and Yu.I. Kuznetsov, Nitrogen-containing five-membered heterocyclic compounds as corrosion inhibitors for metals in solutions of mineral acids - An overview, Int. J. Corros. Scale Inhib., 2021, 10, no. 2, 480-540. doi: 10.17675/23056894-2020-10-2-2

24. A.I. Altsybeeva, E.A. Tronova and V.V. Burlov, Hydrocarbon-soluble metal corrosion inhibitors. II. Physicochemical aspects of inhibitor action. Amides and salts of carboxylic acids, Int. J. Corros. Scale Inhib., 2014, 3, no. 3, 160-166. doi: 10.17675/2305-68942014-3-3-160-166 